\title{
¿TIENEN CABIDA LAS DEFENSAS DE EFICIENCIA EN RELACIÓN A LAS VARIABLES COMPETITIVAS DEL ARTÍCULO 3, LETRA A) DEL DECRETO LEY NúMERO 211? UNA LECTURA DE COMPATIBILIDAD CON LA REGLA PER SE
}

\author{
Are Efficiency Defenses Allowed in Respect to the Competitive Variables of Article 3 Letter a) of
} Decree Law Number 211? A Compatibility Interpretation with the per se rule

\author{
MANFRED ZINK PAPIC ${ }^{1}$ \\ Universidad Andrés Bello
}

RESUMEN

La Ley № 20.945 reformó la letra a) del artículo 3ㅇ del Decreto Ley № 211 con el objeto de introducir una regla per se para prohibir cierto tipo de acuerdos entre competidores (o carteles), en específico, los acuerdos de precios, cantidad, zonas o cuotas de mercado y afectación de licitaciones. Ello implica que dichos acuerdos son sancionables al comprobarse su existencia, sin atender a la posición de mercado de los actores involucrados o a los efectos anticompetitivos que generen y sin admitirse defensas de eficiencia o procompetitivas. Si bien ello resulta deseable desde una perspectiva de política de competencia, surge la duda de si la nueva norma prohíbe derechamente todo tipo de acuerdos entre competidores sobre las variables referidas o si existe algún espacio para alegar que, en ciertas circunstancias, los acuerdos sobre dichas variables pueden ser socialmente eficientes o beneficiosos. El presente artículo pretende hacerse cargo de dicha pregunta, proporcionando una lectura general del artículo 3ㅇ del Decreto Ley № 211, que permite concordar la deseable existencia de reglas per se en nuestra legislación con la posibilidad de admitir, de forma general, defensas de eficiencia.

\section{PALABRAS CLAVE}

Derecho de la libre competencia, acuerdos entre competidores, regla per se, eficiencias

\section{ABSTRACT}

Law № 20,945 amended Article 3 a) of Decree Law № 211 in order to introduce a per se rule to prohibit certain types of agreements between competitors (or cartels), specifically, agreements about price, quantity, market areas or quota and affectation of tenders. Therefore, such agreements are now punishable with the prove of their existence, without consideration of market power or anti-competitive effects, and foreclosing efficiency or pro-competitive defenses. Although this is desirable from a competition policy perspective, the question arises of whether the new regulation rightly prohibits all kinds of agreements of those types between competitors or if it is possible to argue that in certain circumstances, they can be socially efficient or beneficial. This article aims to provide an answer for that question, by giving a general reading of Article 3 of Decree Law № 211, which allows the complementation of per se rules in our legislation with the possibility of admitting efficiency defenses.

\section{KEYWORDS}

Competition Law, Agreements Between Competitors, Per Se Rule, Efficiencies

\section{Introducción}

La Ley № 20.945, de 2016, modificó la letra a) del inciso 2으 del artículo 3으 del Decreto con Fuerza de Ley № 1 del Ministerio de Economía, Fomento y Turismo de 2015, que fija el texto

\footnotetext{
${ }^{1}$ Licenciado en Derecho, Pontificia Universidad Católica de Chile (2003). Abogado (2006). LL.M Universidad de California, Berkeley (2011). Afiliación: Universidad Andrés Bello, Santiago, Chile. Profesor de los cursos de Orden Público Económico y Derecho de la Libre Competencia. Empleador: Fiscalía Nacional Económica, Jefe de la Unidad de Fiscalización de Cumplimiento. Correo electrónico: manfredzink@gmail.com. Las opiniones expresadas en este artículo son de exclusiva responsabilidad del autor y no representan necesariamente el pensamiento de su empleador, la Fiscalía Nacional Económica.
} 
refundido, coordinado y sistematizado del Decreto Ley № 211 de 1973 (en adelante, "DL 211"), estableciendo que en los casos de acuerdos entre competidores (carteles o acuerdos colusorios) sobre precios, cantidades, zonas o cuotas de mercado o licitaciones se eliminaba el requisito de que los mismos confirieran poder de mercado para ser sancionables (en adelante, "la modificación legal" o "la reforma"), lo que, como se expondrá más adelante, implica, tal como pretendió la referida ley, sujetarlos a una regla per se, esto es, que son ilícitos por su sola existencia, sin importar los efectos anticompetitivos que produzcan y sin que se acepten, a su respecto, defensas de eficiencia o justificaciones pro-competitivas.

El texto específico que propuso la reforma, indicando que se considerarían ilícitos los "...acuerdos o prácticas concertadas que involucren a competidores entre sí, y que consistan en fijar precios de venta o de compra, limitar la producción, asignarse zonas o cuotas de mercado o afectar el resultado de procesos de licitación..." y que fuera el finalmente adoptado, suscitó dudas en la tramitación legislativa, en la cual algunos participantes indicaron que podría hacer cuestionar la legalidad de ciertos acuerdos habituales en los negocios y normalmente no cuestionados por la autoridad de competencia, tales como acuerdos de compra de pequeños productores para mejorar su poder de negociación, los coaseguros (contrato de seguro suscrito por varios coaseguradores con un asegurado) y los créditos sindicados (crédito que, por su alto monto, es otorgado conjuntamente por dos instituciones financiera), todos los cuales implican la fijación conjunta de precios².

Dudas similares también fueron levantadas por parte de la doctrina ${ }^{3}$, en el sentido de que la redacción legal parece no dar espacio a que pueda argumentarse que ciertos acuerdos específicos sobre precios, cantidades, zonas o cuotas de mercado y licitaciones pueden ser socialmente eficientes y deseables al, por ejemplo, aumentar la producción en el mercado, reducir costos de transacción o facilitar el desarrollo de ciertos productos.

Dicho tipo de acuerdo reciben generalmente el nombre de acuerdos de colaboración entre competidores y entre ellos se pueden nombrar acuerdos referidos a desarrollo e investigación de productos, a distribución o a comercialización, siendo generalmente aceptado por la doctrina y práctica comparada que pueden generar tanto riesgos como eficiencias, razón por la cual se realiza un análisis más a fondo de los mismos, no compatible con la regla per se ${ }^{4}$.

Como se puede entender, el no realizar un análisis que sopese riesgos y eficiencias podría llevar a una aplicación sobre inclusiva del tipo de la primera parte de la letra a), cometiéndose errores tipo I o falsos positivos, al terminar sancionándose conductas que finalmente redundan en beneficios para los consumidores. Ello desincentivaría, a final de cuentas, la misma realización de dichas conductas eficientes.

Así, surge la pregunta si, de acuerdo al texto legal, es o no posible introducir un análisis de eficiencias en el marco del examen jurídico de acuerdos sobre precios, cantidades, zonas, territorios o licitaciones.

Para tratar adecuadamente el cuestionamiento anterior, el presente artículo se estructura de la siguiente forma. En el capítulo II, se dará una breve explicación de las reglas per se en materia de competencia y se describirá la reforma legal en comento. En el capítulo III, se hará referencia al rol de las justificaciones pro-competitivas o de eficiencia en materia de libre competencia. En el capítulo IV, se expondrán algunas interpretaciones doctrinarias sobre cómo introducir defensas de eficiencia en relación a la letra a), explicitando por qué, en nuestra opinión, no se sostienen teóricamente y/o presentan graves problemas desde el punto de vista

\footnotetext{
2 Primer Informe de la Comisión de Economía: "1. Hay conductas colaborativas entre competidores que son eficientes y el proyecto no las reconoce. Por ejemplo, almacenes chicos que se juntan para negociar mejores precios con los proveedores y competir mejor contra las grandes cadenas", BIBLIOTECA DEL CONGRESO NACIONAL DE CHILE (2016), p. 384. Asimismo: “...con el fin de facilitar la persecución de la colusión el PL incluye entre las conductas prohibidas tanto conductas ilícitas como conductas legítimas. Existe una gran cantidad de situaciones donde la colaboración entre competidores, no solo es legítima, sino también pro-competitiva", citando como ejemplo a los "Créditos Sindicados y coaseguros", BIBLIOTECA DEL CONGRESO NACIONAL DE CHILE (2016), pp. 402-403.

${ }^{3}$ Véase, por ejemplo, WHISH (2015), p. 11.

${ }^{4}$ Para un detalle respecto del tratamiento en doctrina de dicho tipo de acuerdos, véase GRUNBERG (2020), pp. 2-11 y SALOP (2016), pp. 2-7.
} 
de la política pública de competencia. Por último, en el capítulo $\mathrm{V}$, se presenta una lectura congruente y funcional del artículo 3 으, basada en la técnica y lógica legislativa ya asentada del mismo y en la jurisprudencia previa. Dicha lectura permite la coexistencia general de reglas per se en nuestra legislación, admitiendo a la vez hipótesis de defensas de eficiencia.

\section{Reglas per se en materia de libre competencia y su introducción en el DL 211 mediante la Ley № 20.945}

Como regla general, las conductas anticompetitivas se analizan bajo la denominada regla de la razón, en virtud de la cual se debe acreditar: i) la existencia de la conducta; ii) la tenencia de posición de dominio o poder de mercado sustancial y; iii) efectos anticompetitivos en el mercado, esto es, que la conducta produjo resultados contrarios al funcionamiento eficiente del mismo. De acuerdo a ello, la utilización de la regla de la razón implica realizar también un análisis respecto de las eficiencias de la conducta para los consumidores.

La aplicación de la denominada regla per se corresponde a una decisión de política pública, consistente en limitar el análisis, para algunos casos, a la sola acreditación de la conducta anticompetitiva, sin exigencias de probar en detalle el mercado relevante (y la tenencia de poder de mercado en el mismo) y de demostrar los efectos anticompetitivos en el mercado.

Asimismo, la aplicación de la regla per se implica la imposibilidad de alegar defensas de eficiencia o, al menos, su reducción sustancial. Ello por cuanto la experiencia previa dicta que los casos en que se aplica la regla constituyen restricciones flagrantes a la competencia (o manifiestamente anticompetitivas) que no dan pie a eficiencias en el mercado (inequívocamente ineficientes) y, por el contrario, dañan invariablemente la eficiencia social del mismo ${ }^{5}$. Tal es el caso de, por ejemplo, un acuerdo entre dos competidores con el fin de eliminar la competencia entre ellos y alzar los precios a público de sus productos.

Por otro lado, eximir de la aplicación de la regla de la razón a ciertos acuerdos, hace más efectiva la persecución de los mismos al disminuir los costos de esta. Asimismo, es eficiente al dar una idea clara de qué conductas se quieren desincentivar ${ }^{6}$.

En dicho sentido, tratándose de restricciones flagrantes, el riesgo de que el sistema incurra en los denominados errores tipo I (sancionar conductas eficientes) es bajo, pues es improbable que existan razones pro-competitivas o de eficiencia para dicho tipo de conductas. Por tanto, se razona que la política de persecución debiera enfocarse en evitar que los acuerdos anticompetitivos continúen en funcionamiento en el mercado (evitar errores tipo II)7.

Pues bien, en dicha línea, el objetivo explícitamente declarado de la reforma, tanto en el mensaje del proyecto de ley, como durante la tramitación legislativa del mismo, fue el de introducir una regla per se en nuestra legislación para sancionar ciertos acuerdos anticompetitivos desnudos o duros, a los que calificó como exentos de justificaciones de eficiencia ${ }^{8}$.

\footnotetext{
${ }^{5}$ Para mayores detalles sobre la regla per se y su evolución jurisprudencial comparada, véase BORK (1966); HOVENKAMP (2018) y BRUZZONI y CAPOZZI (2015), pp. 217-236.

${ }^{6}$ AREEDA (1981), p. 22: “Una prohibición categórica ofrece una instrucción clara a los hombres de negocios, garantiza sanciones fuertes contra los violadores y así disminuye la posibilidad de que la práctica perniciosa de fijación de precios se lleve a cabo". Traducción libre.

${ }^{7}$ Véase, TAPIA (2010), p. 32.

${ }^{8}$ Así, en el Mensaje del Proyecto se indicó lo siguiente: “d. Eliminación de la exigencia de que el acuerdo o la práctica concertada confieran poder de mercado para sancionar ilícitos de colusión (...)”. El literal a) del inciso segundo del artículo 3o (...) exige que para sancionar un ilícito de colusión, el acuerdo o la práctica concertada deben conferir poder de mercado a los competidores que participen en él. (...) En el derecho comparado se ha establecido que para el caso de los denominados carteles duros (hardcore cartels), (...) resulta suficiente, para que el acuerdo sea declarado como anticompetitivo y contrario a la ley, que se acredite su existencia y que verse sobre las variables esenciales de competencia antes mencionadas. Dicho de otra manera, dado que se concibe a los carteles duros como prácticas manifiestamente anticompetitivas, los tribunales están autorizados a condenar a quienes incurran en ellas sin necesidad de que se realice un completo análisis del mercado relevante ni de su efecto anticompetitivo, siendo además improcedente que el requerido o demandado invoque defensas de eficiencia, que, en rigor, son inexistentes", BIBLIOTECA DEL CONGRESO NACIONAL DE CHILE (2016), p. 6.
} 
La forma en que se decidió introducir dicha regla fue mediante la eliminación del requisito, a la fecha existente, de que dichos acuerdos, para ser sancionables, debían conferir poder de mercado a sus integrantes. Para entender ello adecuadamente, resulta necesario hacer una referencia general al artículo 3 del DL 211, para luego pasar a explicar la reforma.

El inciso $1^{\circ}$ del artículo 30 del DL 211 contiene el denominado tipo de ilícito anticompetitivo genérico o universal, en los siguientes términos:

El que ejecute o celebre, individual o colectivamente cualquier hecho, acto o convención que impida, restrinja o entorpezca la libre competencia, o que tienda a producir dichos efectos, será sancionado con las medidas señaladas en el artículo 26 de la presente ley (...).

Por su parte, el inciso 20 de la misma norma contiene una enumeración no taxativa de hechos, actos o convenciones que, de acuerdo al texto legal, "se considerarán" como contrarios al tipo genérico citado. En forma anterior a la modificación legal introducida por la Ley № 20.945, la letra a) del artículo 3ㅇindicaba (en adelante "letra a)"):

\footnotetext{
a) Los acuerdos expresos o tácitos entre competidores, o las prácticas concertadas entre ellos, que les confieran poder de mercado y que consistan en fijar precios de venta, de compra u otras condiciones de comercialización, limitar la producción, asignarse zonas o cuotas de mercado, excluir competidores o afectar el resultado de procesos de licitación.
}

La Ley № 20.945 estableció una nueva redacción de la letra a), en los siguientes términos:

Se considerarán, entre otros, como hechos, actos o convenciones que impiden, restringen o entorpecen la libre competencia o que tienden a producir dichos efectos, los siguientes:

a) Los acuerdos o prácticas concertadas que involucren a competidores entre sí, y que consistan en fijar precios de venta o de compra, limitar la producción, asignarse zonas o cuotas de mercado o afectar el resultado de procesos de licitación, así como los acuerdos o prácticas concertadas que, confiriéndoles poder de mercado a los competidores, consistan en determinar condiciones de comercialización o excluir a actuales o potenciales competidores.

Como se puede apreciar, la modificación legal introdujo una distinción, categorizando a los acuerdos o prácticas concertadas entre competidores (en adelante, "acuerdos") en dos tipos:

(i) Aquellos cuya configuración típica no requiere de la demostración de que confirieron poder de mercado a los participantes del acuerdo ( 3 o letra a), primera parte).

De acuerdo al texto legal, la primera categoría aplica únicamente a los acuerdos consistentes en fijar precios de venta o de compra, limitar la producción, asignarse zonas o cuotas de mercado y afectar el resultado de procesos de licitación. Este tipo de acuerdos corresponden a los que el proyecto de Ley denominó carteles duros, carentes de toda justificación de eficiencia.

(ii) Aquellos cuya configuración típica sí requiere de la demostración de que confirieron poder de mercado a los participantes del acuerdo ( 3 o letra a), segunda parte).

De acuerdo a la norma que venimos citando, estos acuerdos son aquellos consistentes en determinar condiciones de comercialización y excluir a actuales o potenciales competidores.

Como se entiende lógicamente, esta categoría debe comprender acuerdos consistentes en determinar condiciones de comercialización distintas de aquellas comprendidas en la primera categoría de acuerdos duros, esto es, no podrían referirse a precios, producción o zonas o cuotas de mercado o condiciones en licitaciones.

Por tanto, debe tenerse presente que la reforma legal solo eliminó un requisito de configuración típica para los acuerdos sobre precios, producción, zonas o cuotas de mercado o afectación de licitaciones, que es que respecto de los mismos deba acreditarse que confieren poder de mercado a los involucrados. Asimismo, dejó expresamente vigente dicho requisito para los acuerdos sobre condiciones de comercialización o exclusión de competidores. 
Por otro lado, la reforma tampoco alteró la lógica jurídica del artículo 3o, compuesto de un tipo general y de ejemplificaciones concretas de vulneraciones dicho tipo, ni consecuentemente, el tratamiento de los efectos anticompetitivos en el inciso 1 o y los literales del inciso 2 .

\section{Rol de las justificaciones pro-competitivas o de eficiencia en el análisis de libre competencia}

El derecho de la libre competencia busca incentivar conductas económicas socialmente eficientes en beneficio de los consumidores, oponiéndose a aquellas acciones que no revisten tal carácter ${ }^{9}$. De acuerdo a la teoría económica, el bienestar social se maximiza en condiciones de competencia perfecta, al lograrse los mayores grados posibles de eficiencia asignativa y productiva, maximizándose en consecuencia también el bienestar de los consumidores ${ }^{10}$.

De dicha forma, el derecho de la libre competencia busca que el proceso competitivo refleje, en la mayor medida posible, los resultados de un mercado en competencia perfecta, interviniendo el mismo cuando se aleja de dicho ideal. Así las cosas, al menos implícitamente, la práctica jurisprudencial ha entendido que el deber de promoción y protección de la libre competencia consagrado en el artículo 10 del DL 211 (que incluye el deber de reprimir las conductas impeditivas, restrictivas o entorpecedores de la misma a que hace referencia el artículo $3^{\circ}$ ) dice relación justamente con la promoción de conductas socialmente eficientes y la consecuente represión de conductas socialmente ineficientes, en perjuicio de los consumidores ${ }^{11}$.

Lo anterior también implica que el diseño de las reglas jurídicas del sistema de libre competencia busque aplicar categorías de análisis que maximicen la consecución de sus objetivos, disuadiendo en el mayor grado posible aquellas conductas socialmente ineficientes. Pues bien, aquel es justamente el objetivo de las reglas per se. Por un lado, desincentivar la ocurrencia de conductas inequívocamente ineficientes y, por otro, facilitar la persecución de las mismas.

En dicho sentido, el derecho de la competencia no se opone a todo tipo de acuerdos entre competidores, sino solo a aquellos ineficientes socialmente. De ellos, un particular grupo de acuerdos están sujetos a la regla per se, siendo aquellos cuyo carácter anticompetitivo se encuentra probado, no siendo necesario un mayor análisis para dar cuenta de su carácter ineficiente.

No obstante, como ya señalamos, otro tipo de acuerdos, denominados normalmente como acuerdos de colaboración entre competidores, pueden ser, dependiendo de sus particulares características y circunstancias, tanto beneficiosos socialmente, como dañinos, requiriéndose en cada caso de un análisis que sopese sus beneficios o eficiencias en relación a sus riesgos o efectos negativos. Dicho tipo de acuerdos pueden recaer sobre alguna de las variables competitivas catalogadas como per se por la reforma.

La referida dualidad es reconocida por el derecho comparado. Así, las Directrices de la Comunidad Europea indican expresamente que los “...acuerdos de cooperación horizontal pueden dar lugar a beneficios económicos sustanciales, en especial si combinan actividades,

\footnotetext{
${ }^{9}$ Véase WHISH y BAILEY (2012), p. 1: “Como una proposición general, el derecho de la libre competencia consiste en reglas que intentan proteger el proceso competitivo con el fin de maximizar el bienestar del consumidor". Traducción libre. Para una discusión sobre los distintos fines del derecho de la competencia y la conveniencia de considerar que su fin último es el bienestar de los consumidores, véase, SALOP (2010), pp. 336-353 y HOVENKAMP (2019).

${ }^{10}$ WHISH y BAILEY (2012), p. 4: "Bajo competencia perfecta los recursos económicos son asignados entre distintos bienes y servicios de tal forma que no es posible mejorar el estado de nadie sin empeorar el de otro; el excedente del consumidor - la ganancia neta para un consumidor cuando compra un producto - está en su máximo". Traducción libre.

${ }^{11}$ Véase, por ejemplo, Tribunal de Defensa de la Libre Competencia, resolución 43-2012, de 12 de diciembre de 2012 y sentencias 97-2010, de 4 de marzo de 2010 y 140-2014, de 4 de noviembre de 2014.
} 
conocimientos o activos complementarios ${ }^{12}$, pero que, por otra parte, dichos acuerdos "pueden plantear problemas de competencia. Así ocurre, por ejemplo, cuando las partes acuerdan fijar los precios o la producción o repartirse los mercados ${ }^{13} . . . "$. Un razonamiento similar consta en la guía conjunta de las agencias de competencia de Estados Unidos, el Department of Justice y la Federal Trade Commission, sobre acuerdos de colaboración entre competidores ${ }^{14}$.

El caso europeo resulta particularmente ejemplificador para los fines del presente trabajo. Ello por cuanto la norma que sanciona los carteles o acuerdos entre competidores, el artículo 101, del Tratado de la Comunidad Europea, señala, en su apartado primero, que "...quedarán prohibidos todos los acuerdos entre empresas (...) que tengan por objeto o efecto impedir, restringir o falsear el juego de la competencia dentro del mercado interior"15, sin perjuicio de lo cual, el apartado tercero agrega que "Ias disposiciones del apartado 1 podrán ser declaradas inaplicables..." con respecto a acuerdos "...que contribuyan a mejorar la producción o la distribución de los productos o a fomentar el progreso técnico o económico, y reserven al mismo tiempo a los usuarios una participación equitativa en el beneficio resultante...", entre otros requisitos ${ }^{16}$.

Explicando dicha técnica legislativa, Whish y Bailey indican, siguiendo a la Corte General de la Unión Europea, que ex ante no existen acuerdos, sea cual sea la variable competitiva afectada, respecto de los cuáles no pueda alegarse que satisfacen las justificaciones de eficiencias del apartado 3 del artículo $101^{17}$.

Lo anterior es sin perjuicio de una práctica jurisprudencial europea largamente desarrollada sobre las llamadas restricciones por objeto, asimilables en alguna medida a restricciones per se, respecto de los cuáles la posibilidad de realizar defensas de eficiencia es, en la práctica, bastante reducida o inexistente, por la naturaleza misma del acuerdo en cuestión ${ }^{18}$. Pero más allá de ello, en lo relevante para el presente trabajo, el derecho europeo reconoce legislativamente la posibilidad de demostrar eficiencias en relación acuerdos entre competidores, con independencia de la variable competitiva afectada, entendidas como mejoras en la producción o distribución de los productos, así como en el fomento del progreso técnico o económico, siempre que las mismas redunden en beneficios para los consumidores o usuarios.

Por otra parte, en Estados Unidos, en materia de acuerdos entre competidores, ha sido la evolución jurisprudencial la que ha ido delimitando qué clase de acuerdos constituyen restricciones "desnudas" (naked restrictions), esto es, carentes de justificación plausible de eficiencia y, por tanto, considerados una restricción per se al comercio y, cuáles, en cambio, deben ser analizados utilizando la regla de la razón, sopesando, por tanto las eventuales eficiencias de los mismos ${ }^{19}$.

No obstante, la evolución jurisprudencial estadounidense ha demostrado que el carácter per se de una restricción no depende exclusivamente de la variable competitiva afectada. Así, por ejemplo, si bien se acepta generalmente que la fijación de precios (price fixing) es la conducta sujeta a regla per se por antonomasia, las Cortes han analizado casos de acuerdos de precios bajo la regla de la razón, aceptando su legitimidad en virtud de su carácter eficiente.

\footnotetext{
12 COMISIÓN EUROPEA (2011), p. 4: “La cooperación horizontal puede ser un medio de compartir el riesgo, ahorrar costes, incrementar las inversiones, agrupar los conocimientos técnicos, aumentar la calidad y variedad del producto y lanzar más rápidamente la innovación".

${ }^{13}$ COMISIÓN EUROPEA (2011), p. 4.

${ }^{14}$ FEDERAL TRADE COMMISSION y U.S. DEPARTMENT OF JUSTICE (2000)

${ }^{15}$ Artículo 101 (1) del Tratado de Funcionamiento de la Unión Europea.

${ }^{16}$ Artículo 101 (3) del Tratado de Funcionamiento de la Unión Europea.

17 WHISH y BAILEY (2012), p. 121. En el mismo sentido MORAIS (2013), p. 87: “Como ha sido reconocido ampliamente, los carteles pueden ser solo excepcionalmente justificados bajo el para. (3)". Asimismo, véase FAULL et al. (2014), p. 235.

18 Véase, por ejemplo, Tribunal de Justicia de la Comunidad Europea, caso C-307/18, de 30 de enero de 2020, Generics (UK) Ltd y otros contra Competition and Markets Authority: "De acuerdo a ello, en relación a las practicas caracterizadas como restricciones por objeto, no existe necesidad de investigar sus efectos...".

${ }_{19}$ Para un detalle de dicha evolución jurisprudencial, véase BORK (1966) y HENRY (2016).
} 
Un caso paradigmático a dicho respecto es Broadcast Music, Inc. v. Columbia Broadcasting System, Inc. ${ }^{20}$, en el cual la Corte Suprema de Estados Unidos indicó lo siguiente: "La literalidad es demasiado simplista y regularmente sobrecargada. Cuando dos socios determinan el precio de sus bienes o servicios están literalmente fijando precios, pero no están violando la Ley Sherman en forma per se"21.

En dicha ocasión, analizando la Corte un acuerdo de fijación de tarifas de licencias musicales, efectuado por una entidad de gestión colectiva de derechos de autor ${ }^{22}$, indicó que el mismo, pese a constituir un acuerdo de precios, no podía calificarse como per se por cuánto no constituía una restricción desnuda al comercio sin otro objeto que el de restringir la competencia, al permitir a los autores de obras musicales disminuir en forma considerable costos de transacción para la negociación de sus licencias, especialmente en lo referido a costos de negociación, monitoreo y ejecución ${ }^{23}$. En otras palabras, razonó la Corte que el referido mecanismo poseía eficiencias, razón por la cuál debía analizarse bajo la regla de la razón.

La consideración sobre la eficiencia de la conducta sujeta a escrutinio en materia de libre competencia también resulta relevante respecto de conductas anticompetitivas distintas de los acuerdos entre competidores. Así, en materia de operaciones de concentración, el test estándar utilizado por las autoridades a nivel mundial es uno que intenta determinar los efectos anticompetitivos que generaría la operación y los contrapesa con las potenciales eficiencias de la misma ${ }^{24}$. Si se concluye que las eficiencias son mayores a los riesgos, y que las mismas son traspasables a los consumidores, se acepta generalmente la materialización de la operación ${ }^{25}$.

Por su parte, en lo que respecta a los abusos de posición de dominio o a las restricciones verticales, se acepta generalmente que una conducta abusiva es aquella que excluye a los competidores o explota a los consumidores, sin una justificación razonable de eficiencia o cuyos efectos anticompetitivos son mayores a sus eficiencias. Por el contrario, si la referida conducta genera, a la larga, eficiencias que benefician a los consumidores, aunque excluya competidores, no será ilícita ${ }^{26}$.

De dicha forma, en todas las áreas del derecho de la competencia resulta relevante determinar si la conducta es eficiente socialmente o no. Ello en caso alguno se opone a la existencia de las reglas per se. Por el contrario, desde un punto de vista sustantivo, las mismas se justifican esencialmente en consideraciones sobre la eficiencia (inexistente) de la conducta a la cual se aplican y, desde una perspectiva adjetiva, en la mayor eficiencia (menores costos) que acarrean para el sistema.

De acuerdo a lo anterior, la pregunta que origina este artículo cobra relevancia. En efecto, los objetivos del derecho de la libre competencia y consideraciones de eficiencia, tanto sustantiva como procedimental, requieren idealmente que, en materia de acuerdos entre competidores, el diseño del sistema jurídico permita la coexistencia de reglas per se con la

\footnotetext{
${ }^{20}$ Broadcast Music, Inc. v. Columbia Broadcasting System, Inc. 441 U.S. 1, 9 (1979).

${ }^{21}$ Broadcast Music, Inc. v. Columbia Broadcasting System, Inc. 441 U.S. 1, 9 (1979).

22 Dicho tipo de entidades agrupan licencias de una serie de autores, fijando normalmente un mismo precio por las mismas y negociándolas en bloque, consiguiendo ahorros de costos.

${ }^{23}$ Broadcast Music, Inc. v. Columbia Broadcasting System, Inc. 441 U.S. 1, 9 (1979).

${ }^{24}$ De acuerdo a la FNE (2012), p. 22: "Las eventuales eficiencias que puedan emanar como consecuencia de una operación de concentración pueden representar un contrapeso a los riesgos aparejados a la misma".

${ }^{25}$ Así, por ejemplo, Tribunal de Defensa de la Libre Competencia, resolución 43-2012, de 12 de diciembre de 2012: “...las eficiencias alegadas deben redundar, al menos en parte y con probabilidad y plazo razonables, en menores precios para los consumidores o en una mejora en la calidad de los productos o servicios ofrecidos...".

${ }^{26}$ Véase, por ejemplo, HOVENKAMP (2008), p. 1: "Definimos conducta monopolística como actos que:

(1) son razonablemente capaces de crear, aumentar o prolongar el poder de mercado al desmejorar las oportunidades de los rivales; y (2) que (2a) no benefician a los consumidores, o (2b) son innecesarios para los beneficios a los consumidores que se les as ignan (...)". En un sentido similar, refiriéndose al artículo 102 que contempla los abusos de posición de dominio en el derecho europeo, DE LA MANO et al. (2014), p. 332: "Su propósito es más bien prohibir conducta que directamente al explotar a los consumidores o indirectamente al excluir competidores, reduce el bienestar social...".
} 
posibilidad de analizar la eficiencia de un acuerdo, con independencia de la variable competitiva específica afectada.

Ello por cuánto, por un lado, las reglas per se permiten disuadir conductas dañinas e ineficientes, así como reducir los costos administrativos del sistema y, por otro, sin la posibilidad de realizar un análisis de eficiencias simplemente no existiría forma alguna de que ciertos acuerdos sobre las variables de la letra a) del artículo 3o, que son eficientes socialmente, subsistan bajo nuestra tipificación actual, viéndose el mercado y los consumidores privados de los beneficios de dicho tipo de acuerdos.

\section{Algunas interpretaciones que se han planteado para introducir un análisis de eficiencia en el artículo 3으, letra a)}

Se han argumentado al menos dos soluciones interpretativas con el objeto de intentar introducir un espacio de justificaciones pro-competitivas a la primera parte de la letra a): i) considerar que los ejemplos de conductas del inciso 20 operan por remisión al tipo general antimonopólico del inciso 1으, por lo que siempre deberá acreditarse que afectan la competencia, lo que conllevaría a su vez el deber de descartar eventuales justificaciones pro-competitivas y; ii) estimar que el artículo 3 letra a) contiene una presunción legal, por lo que se admitiría prueba en contrario, de carga del requerido o demandado.

Como desarrollaremos a continuación, las interpretaciones referidas nos parecen contrarias a la literalidad del artículo 3 , a su lógica jurídica y a la historia fidedigna del establecimiento del precepto legal. Asimismo, estimamos que son problemáticas desde un punto de vista de una política de competencia óptima.

Improcedencia de introducir justificaciones pro-competitivas por vía de remisión al artículo 30 inciso primero

Como ya señalamos, el artículo 3을 inciso 10 del DL 211 contiene el denominado tipo general del ilícito anticompetitivo, en los siguientes términos:

El que ejecute o celebre, individual o colectivamente cualquier hecho, acto o convención que impida, restrinja o entorpezca la libre competencia, o que tienda a producir dichos efectos, será sancionado con las medidas señaladas en el artículo 26 de la presente ley, sin perjuicio de las medidas preventivas, correctivas o prohibitivas que respecto de dichos hechos, actos o convenciones puedan disponerse en cada caso.

Así las cosas, cualquier acción (hecho, acto o convención) que vulnere la libre competencia (la impida, restrinja o entorpezca) o que tienda a producir dicha vulneración, constituye un ilícito anticompetitivo. Como se ha señalado, la amplitud del tipo resulta justificada atendida la naturaleza esencialmente dinámica de los mercados y la consecuente multiplicidad y complejidad de las conductas que pueden atentar contra la libre competencia ${ }^{27}$. En efecto, una técnica legislativa opuesta, consistente en enumerar distintos ilícitos anticompetitivos taxativamente, corre el riesgo de ser deficiente al no capturar conductas que efectivamente afectan la libre competencia, pero no son subsumibles estrictamente en la taxonomía legal.

Ahora bien, complementando la técnica legislativa amplia del inciso 1으 del artículo 3o, el inciso 2 o del mismo artículo proporciona ejemplos determinados, no taxativos, de conductas que vulneran la libre competencia o que tienden a ello, esto es, debemos entender, de casos particulares en que se ve concretizado el tipo universal de ilícito competitivo, en los siguientes términos:

${ }^{27}$ Veáse, VALDÉS (2007), pp. 241 y ss. Asimismo, Tribunal de Defensa de la Libre Competencia, resolución 18-2016, de 16 de noviembre de 2006. 
Se considerarán, entre otros, como hechos, actos o convenciones que impiden, restringen o entorpecen la libre competencia o que tienden a producir dichos efectos, los siguientes:

(...).

La referida técnica legislativa ha llevado a argumentar a algunos académicos ${ }^{28}$ que, dado que todos los literales son ejemplos del tipo general del inciso 10 y ese tipo requiere que se afecte la libre competencia, al invocarse cualquier literal del inciso 2으, entre ellos la letra a), siempre debe demostrarse o probarse dicha afectación o la tendencia a la misma. Ello implicaría, en la práctica, tener que demostrar poder de mercado y efectos negativos sobre la competencia o una tendencia a los mismos. Como corolario, atendido que una conducta eficiente no vulnera la libre competencia, siempre habría espacio para defensas de eficiencia.

Dicha postura fue recogida por en un voto de prevención en un reciente fallo del Honorable Tribunal de Defensa de la Libre Competencia ("TDLC"), en la que señaló expresamente que:

\begin{abstract}
...la letra a) del inciso segundo del artículo 3o del D.L. 211, no establece una regla per se en materia de colusión. Ello debido a que el inciso primero del artículo tercero establece que: "El que ejecute o celebre, individual o colectivamente cualquier hecho, acto o convención que impida, restrinja o entorpezca la libre competencia, o que tienda a producir dichos efectos, será sancionado con las medidas señaladas en el artículo 26 de la presente ley... ". De esta forma para sancionar las conductas a las que hace mención el artículo tercero, es necesario probar que éstas impiden, restringen o entorpecen la libre competencia o tienden a ello 29.
\end{abstract}

En nuestra opinión, la argumentación anterior no puede prosperar, en primer término, por el claro tenor legal. Ello por cuanto el encabezado del inciso 20 deja en claro que en los casos que enumera y siempre que se cumpla con los requisitos típicos de cada letra, "[S]e considerará (...)", que se produce un impedimento, restricción o entorpecimiento de la libre competencia o una tendencia a ello. Luego, si se verifican en el caso particular los requisitos típicos específicos de cada literal, se produce una afectación de la libre competencia, sea actual o potencial, por expresa disposición legal.

En dicho sentido, los literales a) a d) son casos concretos de infracciones a la libre competencia que se bastan a sí mismos, no procediendo interpretarlos o darles contenido por reminiscencia al inciso 1ํㅡ, por cuanto el legislador ya indicó que, en esos casos, el tipo universal antimonopólico se especificaba de la forma detallada en cada literal, cuestión que ha sido reconocida expresamente por el $\mathrm{TDLC}^{30}$. Estimamos que, desde la lógica y la semántica, la expresión "[S]e considerará (...)" es clara y no admite otra interpretación posible. Así, el encabezado del inciso 20 deja en claro que en los casos que enumera y siempre que se cumpla con los requisitos típicos de cada letra, "[S]e considerará (...)", que dichos efectos anticompetitivos se producen o que se tiende a ello.

Así, por ejemplo, la letra b) del artículo 3, requiere que se demuestre posición de dominio, pero no como una exigencia general del inciso 1 을 de dicho artículo, sino por ser parte de los requisitos específicos de dicho tipo. La doctrina y jurisprudencia más autorizada apoya lo que hemos sostenido en este punto ${ }^{31}$.

\footnotetext{
${ }^{28}$ Véase, por ejemplo, opinión de Tomás Menchaca en TRIBUNAL DE DEFENSA DE LA LIBRE COMPETENCIA (2016), p. 15.

29 Tribunal de Defensa de la Libre Competencia, resolución 54-2018, de 31 de octubre de 2018, voto de prevención de la Ministra Domper.

${ }^{30}$ Véase, por ejemplo, Tribunal de Defensa de la Libre Competencia, sentencias 145-2015, de 1 de abril de 2015 y $167-2019$, de 28 de febrero de 2019.

31 Véase, por ejemplo, BASCUÑÁN (2016), p. 182: “(...) lo que se encuentra excluido por una interpretación sistemática de las relaciones entre el inciso primero y el inciso segundo del Art. $3^{\circ}$ del DL 211 (...) es las tesis de que las normas que describen los "casos ejemplares" sin asociar consecuencias jurídicas especiales a su realización determinan elementos de la infracción adicionales a los elementos del supuesto de hecho genérico y constriñen al requirente o al demandante y al TDLC a subsumir el comportamiento bajo dicha norma, intensificando la carga de la prueba...". En el mismo sentido, Corte Suprema, Rol N²578-2012, de 07 de septiembre de 2012: "Respecto de la norma del artículo $3^{\circ}$ del Decreto Ley 211, el legislador, luego de describir con detalle la
} 
De dicha forma, estimamos que la estructura lógica y literal del artículo 3 o hace que sea improcedente sostener que en base a la referencia al inciso 10 (esto es, a la necesidad de afectación a la libre competencia) puedan eximirse de la aplicación de la regla per se ciertos acuerdos de precios que tienen efectos pro-competitivos o de eficiencia, como son los acuerdos de colaboración a que nos hemos referido. Si bien podría argumentarse que ello constituye un defecto de técnica legislativa de la Ley № 20.945, ya que una interpretación formalista del texto legal no parece dar espacio a un análisis de eficiencias respecto de dicho tipo de acuerdos, aunque fuere este limitado, calificado y de carga del requerido o demandado, como si existe invariablemente en la práctica extranjera, dicha deficiencia no justifica desatender el sentido y lógica del artículo 3ㅇ (así como la práctica jurisprudencial) mediante una interpretación referencial redundante y contraria al mismo.

Segundo, porque la relevancia de lo expuesto anteriormente es fundamental. En efecto, tal como lo sostiene la citada prevención, el interpretar que los casos ejemplares de los literales a) a d) del artículo 3 o deben configurarse por reminiscencia el inciso 1ㅇ, implica la imposibilidad de aceptar la existencia de una regla per se en nuestra legislación. Así, ello implicaría sostener que respecto de todos los literales del inciso 20 sería aplicable una especie de regla de la razón, al requerir demostrarse probar siempre una afectación de la libre competencia o una tendencia a ello (entendida como poder de mercado y ausencia de eficiencias).

Como se puede entender, ello sería muy costoso desde una perspectiva de política pública de competencia, al requerirse prueba completa incluso en relación a conductas que carecen de toda plausibilidad de eficiencia, como son los carteles duros, cuestión que no tiene mayor sentido y que contraría las mejores prácticas internacionales en la materia.

Tercero, la referida interpretación es también contraria al principio de razonabilidad, al transformar a la reforma legal en una reforma sin sentido ni efecto práctico alguno. En efecto, implicaría que la reforma legal, cuyo objetivo legislativo de introducir una regla per se fue claro y expreso, no tendría en la práctica consecuencia o utilidad alguna, de forma contraria a la historia legislativa del precepto en cuestión.

\section{Improcedencia de considerar que el artículo 3ㅇ, letra a) contiene una presunción legal}

Otra forma de salvar el problema de cómo introducir un espacio de análisis de eficiencias en el 3 o, letra a) sería considerar que la norma corresponde a una presunción legal. De dicha forma, el cumplimiento de los requisitos típicos solo implicaría una presunción de ilicitud, la que admitiría prueba en contrario, dando así un espacio para que los participantes en la conducta demuestren que la misma es pro-competitiva o eficiente.

Así, si la parte demandante logra acreditar el acuerdo típico, se presumirían sus efectos anticompetitivos o la tendencia a los mismos, quedando abierta la posibilidad a la parte demandada de demostrar que el acuerdo produjo eficiencias e, incluso, que los efectos anticompetitivos o la tendencia a los mismos no se produjeron. De dicha forma, los literales serían más bien reglas probatorias, implicando la inversión de la carga de la prueba.

Dicha postura fue esbozada por Bascuñán, aunque en forma previa a la reforma y en relación al texto del artículo 3o, letra a) entonces vigente, indicando que los literales del artículo 3 podrían concebirse como "...reglas probatorias, es decir, como presunciones simplemente legales del carácter lesivo (impeditivo, restrictivo o entorpecedor de la libre competencia) o concretamente peligroso (tendiente a causar efectos) del comportamiento" ${ }^{\prime 32}$.

En dicho sentido, surge una primera objeción a la interpretación que venimos comentando. Tal como se subentiende de la cita anterior, no es posible considerar que la reforma legal introdujo una presunción legal al artículo 3으, letra a), dado que la misma en nada alteró la estructura básica de dicha letra a), ni la relación de dicho literal con el inciso primero y

conducta que sanciona, entrega criterios orientadores de aquello que puede ser considerado atentatorio a la libre competencia, sin que tales regulaciones limiten o restrinjan el tipo general (...)".

32 BASCUÑÁN (2016), p. 180. 
encabezado del inciso segundo del artículo 3‥ Esto es, de considerarse que la técnica legislativa utilizada corresponde a una presunción, es forzoso concluir que la misma ya existía con anterioridad a la reforma legal y que, además, todos los demás literales del inciso segundo serían también presunciones legales.

Más allá de dicha incongruencia, nos parece que considerar que el artículo 3, letra a) contiene una presunción legal conlleva una serie de problemas de consideración.

En primer término, y de forma muy relevante, por cuánto la postura en comento, en la práctica, implica admitir la inexistencia de la regla per se en nuestra legislación de libre competencia. Como ya se ha explicado, es de la esencia de la regla per se el que, una vez que se ha acreditado el acuerdo, debe entenderse necesariamente que los efectos anticompetitivos se producen o tienden a producirse. Ello por cuanto, como ya indicamos, los acuerdos anticompetitivos sujetos a regla per se, son aquellos inequívocamente ineficientes o anticompetitivos.

Por el contrario, el considerar que el artículo 3으, letra a) contiene una presunción legal implicaría simplemente invertir la carga de la prueba, otorgando a los requeridos o demandados no solo un espacio para admitir justificaciones de eficiencia, sino para derechamente discutir la existencia de efectos anticompetitivos o de la tendencia a los mismos. De dicha forma, la eficiencia social de la regla per se en la prevención de carteles, su razón de ser como política pública, se vería disminuida en forma relevante.

Se debe recordar acá que la existencia de reglas per se en materia de libre competencia tiene su razón de ser en que la misma constituye una regulación administrativa, que busca principalmente precaver la ocurrencia de riesgos en los mercados, de la forma más eficiente posible ${ }^{33}$. En dicho sentido, el derecho de la libre competencia persigue un objetivo regulatorio más que sancionatorio: el funcionamiento eficiente de los mercados, de forma de maximizarse el bienestar total y excedente de los consumidores ${ }^{34}$. Por lo mismo, el carácter disuasivo de las normas resulta fundamental para evitar que ciertas conductas nocivas para los mercados efectivamente se produzcan. En relación a ello, una regla per se para los carteles duros provee de mayores grados de disuasión, efecto que disminuye considerablemente de interpretársele como una presunción legal.

En dicha línea, no puede desconocerse además que la interpretación del 3으, letra a) como presunción es contraria al objetivo perseguido expresamente por el legislador de la Ley $\mathrm{N}^{\circ}$ 20.945: aplicar una regla per se a los carteles duros. Por tanto, un entendimiento mínimamente razonable de la reforma legal debería conducir a descartar la argumentación de la presunción legal.

Además, la interpretación en comento tiene un efecto reflejo sobre los demás literales del inciso 2 o del artículo 3ㄴ, cuestión que podría tener efectos perniciosos, sobretodo en relación a su letra d), que prohíbe el interlocking horizontal directo, consistente en la participación simultánea de una persona en cargos directivos o ejecutivos relevantes en dos o más empresas competidoras. En efecto, de aceptarse que los literales del inciso segundo constituyen presunciones, debe aceptarse también que existiría un espacio para alegar eficiencias o ausencia de efectos anticompetitivos en relación a la prohibición consignada en el artículo 3oㅡ, letra d),

\footnotetext{
33 Veáse BARROS (2011), p. 98: “Es práctica común que por vía legislativa o administrativa sean reguladas actividades que presentan riesgos. Las consideraciones que sigue el legislador son esencialmente preventivas. Es el caso de materias tan diferentes como el tránsito de vehículos motorizados (Ley del Tránsito), (...), el funcionamiento justo y eficiente de los mercados en materia de libre competencia (DL 211 / 1973) ...".

${ }^{34}$ Véase MONTT (2017), p. 81, quién señala que, en relación a la protección de la libre competencia, “...existen dos valores fundamentales, la eficiencia económica y la protección de los consumidores, que reclaman una actuación regulatoria a priori, de naturaleza administrativa, de parte de los órganos encargados de velar por la competencia". (...) No es distinto a las regulaciones relativas a la vida, seguridad, salud, medioambiente y otras, donde los fines públicos justifican limitaciones y restricciones a las libertades y derechos", p. 81. En un sentido similar, Corte Suprema, Rol №31.502-2018, de 23 de mayo de 2019: “(...) resulta indudable que el Decreto Ley № 211 presenta una finalidad de carácter económico, entre cuyos objetivos se encuentra la tutela, reglamentación y resguardo de la libre competencia, que forma parte del orden público económico, que ha sido desarrollado en la Constitución, generando un marco regulatorio respecto de la actividad del Estado y de los particulares de protección de las garantías individuales..".
} 
cuestión que también contraría el objetivo que tuvo el legislador al imponer dicha prohibición, de acuerdo a la historia fidedigna del establecimiento de la misma ${ }^{35}$.

Estimamos que ello sería contrario al texto legal, el que claramente tipificó como ilícito el solo hecho de participar ("la participación"), al mismo tiempo ("simultánea"), como director o ejecutivo relevante en dos o más empresas competidoras. Así, la conducta tipificada se configura por dicha participación simultánea y desde el momento en que comienza a verificarse, sin necesidad de demostrar una afectación a la libre competencia, atendidos los riesgos propios que dicha situación conlleva ${ }^{36}$.

Por último, en este punto, debe tenerse presente que el entendimiento de los literales como presunciones no tiene asidero en nuestra jurisprudencia de libre competencia, la que no los ha considerado de tal forma, ni aplicado tal marco de análisis probatorio. Asimismo, tampoco existe asidero para dicha interpretación en la historia fidedigna de la ley y no solo en relación a lo ya señalado con respecto a la ley 20.945, sino también en lo referente a las leyes 19.911 y 20.361, que también introdujeron cambios al artículo 3‥

\section{Hacia una lectura congruente del artículo $3^{\circ}$ letra a)}

Resaltada la inconveniencia de las interpretaciones anteriores y atendido que, como hemos visto, una política de competencia razonable solo querría sancionar con una regla per se a las conductas cuya ineficiencia social está probada, surge la necesidad de ensayar una lectura del artículo 3 ㅇ, letra a) que permita conciliar la coexistencia de una regla per se con la posibilidad de acreditar que ciertos acuerdos de precios, cantidades, zonas o cuotas o licitaciones pueden eventualmente ser eficientes.

\section{La regla per se debe entenderse como una categoría de análisis dentro del marco del artículo 3 o del DL 211, más que una tipología de conductas}

Siguiendo a Hovenkamp, estimamos que la forma correcta de analizar conceptualmente el problema que venimos planteando es la siguiente: aquello que es per se corresponde a una categoría de análisis y no a una tipología de conductas delimitadas por la variable competitiva afectada. En palabras de dicho autor, el concentrarse en las distintas variables competitivas afectadas o en, el caso de Estados Unidos, en los precedentes de casos que han aplicado la regla per se en relación a la variable afectada, sería un enfoque "...mal dirigido porque le asigna demasiado valor a una clasificación formal, en vez de a un modo de análisis"137.

Esto es, dicha regla se justifica en la medida que se aplique a todas aquellas conductas que, de acuerdo a la experiencia previa, son catalogables como plausiblemente ineficientes. En dicho sentido, más allá de la variable competitiva específica que pueda verse afectada, lo esencial es la ineficiencia social de la conducta ${ }^{38}$. Esa es su justificación de política pública ${ }^{39}$, son dichas conductas las que el sistema quiere disuadir y respecto de las cuáles existe claridad respecto de sus efectos anticompetitivos, al punto que los mismos se asumen por la sola concurrencia de la misma.

A dicho respecto, si bien la jurisprudencia y doctrina nacional y comparada muchas veces ha tendido a clasificar las conductas anticompetitivas flagrantes o per se según la variable competitiva afectada, ello no obsta a que de todos modos se reconozca, aunque no siempre

\footnotetext{
${ }^{35}$ Comisión de Constitución del Senado: “(...) el derecho comparado considera que se trata de una situación que es per se peligrosa, razón por la que se debe evitar aunque no haya acuerdo de por medio, y no se produzca ningún efecto anticompetitivo medible", BIBLIOTECA DEL CONGRESO NACIONAL DE CHILE (2016), p. 534.

${ }^{36}$ Véase FNE (2013), pp. 26-32.

${ }^{37}$ HOVENKAMP (2018), p. 97.

${ }^{38}$ HOVENKAMP (2018), p. 97: “Una regla de precedentes bien definida debería aplicar la regla per se a restricciones "desnudas” (...). En contraste, si el caso sugiere realísticamente que las ganancias pueden provenir de menores costos o mejores productos, entonces aplica la regla de la razón. La selección de la regla apropiada debería considerar si existe o no una literatura robusta demostrando que la conducta en cuestión puede ser tanto beneficiosa como dañina". Traducción libre.

39 Véase HOVENKAMP (2018).
} 
expresamente, que el elemento fundamental que gatilla la aplicación de una regla per se es, más allá del tipo de conducta, el carácter ineficiente o pernicioso de la misma Así, se ha indicado por la doctrina nacional que lo "...que introduce (...) el análisis bajo la regla per se, es simplemente un elemento de "obviedad (...) Como he indicado, la restricción a la competencia en estos casos es manifiesta $y$, por el contrario, no existen ventajas evidentes que puedan ni remotamente desvirtuar tal obviedad"40.

Lo anterior implica considerar que los acuerdos entre competidores que pueden ser analizados bajo la letra a) son siempre aquellos que plausiblemente no admiten justificaciones de eficiencia. En dicho sentido, la determinación de si una conducta se analiza o no bajo la letra a) no está demarcada, en primera instancia, por la variable de competencia afectada, sino por su carácter inequívocamente ineficiente. Por lo mismo, acuerdos sobre precios, cantidades o zonas o cuotas de mercado, licitaciones, condiciones de comercialización y exclusión de

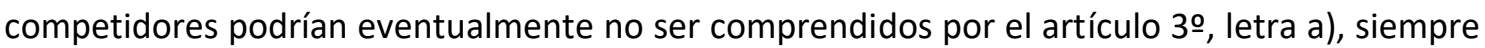
que admitan ex ante una justificación de plausibilidad pro competitiva.

Dicho tipo de acuerdos no inequívocamente ineficientes, serían analizados en base al inciso primero del artículo 3으, haciéndose una comparación entre sus efectos anticompetitivos, actuales o potenciales y las eficiencias asociadas al mismo, siendo procedentes por tanto defensas de eficiencias solo respecto de acuerdos entre competidores no catalogables como aquellos de la letra a) del artículo 3‥

Consideramos que existen una serie de razones legales, doctrinarias y de política de competencia en favor de la interpretación anterior. Fundamentalmente, es la que más se condice con el texto mismo del artículo 3o y la lectura lógica y semántica de sus incisos primero y segundo. En efecto, como ya se ha señalado reiteradamente, la letra a) y los demás literales del inciso segundo son casos en que el legislador considera que la libre competencia se ve afectada o que se tiende a dicha afectación. Esto es, casos en que, acreditados los requisitos típicos, se configura una infracción, sea por afectación directa o tendencia a ello.

Asimismo, como se indicó, la historia legislativa es clara en cuanto a la intención del legislador de introducir una regla per se para ciertos acuerdos que, en su opinión, no podrían admitir justificación plausible de eficiencia. En dicho sentido, sería contraproducente sostener una interpretación del artículo 3o letra a) que, por alguna de las vías que hemos explicado o cualquier otra, dificulte la aplicación efectiva de tal regla.

Adicionalmente, la interpretación que sostenemos es la que mejor se aviene con el desarrollo jurisprudencial en la materia. A dicho respecto, debe tenerse presente que en vigencia del texto legal anterior a la Ley N²0.945, la jurisprudencia del TDLC y la Corte Suprema en materia de acuerdos anticompetitivos ya había ido avanzando hacia un análisis en algún grado parecido al de la regla per se, al no exigir la prueba de efectos anticompetitivos para sancionar un acuerdo entre competidores. Así, por ejemplo, la Corte Suprema había señalado: “(...) De esto surge que no se requiere, para imponer la sanción, que el acto en cuestión haya producido sus efectos, sino que basta que el mismo tienda a producir efectos que afecten la libre competencia..." ${ }^{\prime 4}$.

\footnotetext{
40 TAPIA (2010), p. 32, agregando que: "Esto es, no existe ninguna explicación que pueda legitimar la conducta concertada de las partes: ella es particularmente perniciosa para la competencia". Asimismo, la Corte Suprema ha señalado que la regla per se se aplica a acuerdos "...ilegales por sí mismos, de manera objetiva, absoluta y automática, sin importar su idoneidad o no, o si produjeron o no efectos perjudiciales en el mercado", Corte Suprema, Rol № 2578-2012, 7 de septiembre de 2012. Por su parte, la Corte Suprema de Estados Unidos ha indicado que lo per se corresponde a "...aquella categoría de acuerdos o prácticas que, debido a sus perniciosos efectos para la competencia y a la falta de virtudes que lo justifiquen, son presumidas concluyentemente como irrazonables y por lo tanto ilegales, sin que sea necesario efectuar una indagación elaborada en cuanto al daño preciso que han causado ni a las excusas de negocios que motivan su uso", Northwest Wholesale Stationers v. Pacific Stationary \& Printing Co., 472 U.S. 284, 289 (1985). En lo que se refiere al derecho comunitario europeo, WHISH (2012), p. 122, citando a la jurisprudencia eu ropea, señala: “...la noción de restricción por el objeto no puede reducirse a una lista exhaustiva y no puede limitarse a los ejemplos de acuerdos anticompetitivos dados en el Artículo 101 (1)".

${ }^{41}$ Corte Suprema, Rol № 27.181-2014, de 29 de octubre de 2015. En el mismo sentido, Corte Suprema, Rol № 2578-12, de 07 de septiembre de 2012 y Rol № 5128-2016, de 12 de octubre de 2016. Asimismo, Tribunal de Defensa de la Libre Competencia, sentencias 137-2014, de 19 de junio de 2014, 145-2015, de 1 de abril de 2015 y 148-2015, de 23 de diciembre de 2015.
} 
Ello, en aplicación del texto legal del inciso primero del artículo 3 ㅇ y del encabezado del inciso segundo del mismo artículo, que sancionan conductas que tiendan a afectar la libre competencia, sin exigir necesariamente la producción de un resultado gravoso. En dicho sentido, de acuerdo a la Corte Suprema, "(...) la incorporación de la frase "o que tiendan a producir dichos efectos", (...) transforma todas las figuras enunciativas en un delito de peligro abstracto, al igual que la descripción del inciso primero"42.

Analizando la misma redacción legal, había indicado la doctrina que el hecho de que se sancionen conductas que tiendan a afectar la libre competencia hace que pueda considerarse a la colusión como una infracción de mera actividad ${ }^{43}$ y que, en dicho sentido, "...la ley ha hecho formalmente equivalentes como infracciones a la infracción en grado de peligro y a la afectación en grado de lesión. Es decir, ha anticipado la plena ilicitud del comportamiento, y su sanción, a un estado previo a la lesión del bien jurídico"

Dado lo anterior, resulta entendible por qué razón el legislador decidió consagrar una regla per se mediante la eliminación del requisito de que ciertos acuerdos deban conferir poder de mercado, dado que, como hemos visto, una regla per se exime de la necesidad de acreditar poder de mercado y efectos anticompetitivos y este último requisito no era exigido por nuestra legislación y así lo había reconocido la jurisprudencia. Ello, sin perjuicio de que parte de la doctrina sostenía que, incluso existiendo el requisito de poder de mercado, era posible dar cabida a una regla per se en nuestra legislación ${ }^{45}$. No obstante, en la práctica, el TDLC siempre exigió la prueba del poder de mercado e incluso absolvió a involucrados en acuerdos por no haberse acreditado dicho requisito, cuestión que no fue siempre compartida por la Corte Suprema ${ }^{46}$.

Así las cosas, estimamos que la reforma legal otorgó claridad relevante a dicho respecto, al eliminar expresamente de la configuración típica del artículo 3, letra a) un requisito tradicionalmente asociado al análisis bajo la regla de la razón y que había suscitado dudas en su aplicación. Ello, por lo demás, tiene asidero en la doctrina comparada ${ }^{47}$.

Más allá de lo anterior, lo relevante para la tesis del presente artículo es que, atendido que la estructura e interrelación de los incisos 1 ㅇ y 2 ㅇ del artículo 3 음 no fueron modificados por la reforma, la interpretación que sostenemos permite un entendimiento de continuidad entre ambos momentos normativos: la letra a), así como los demás literales, siempre contuvo una concreción específica de una conducta que, concurriendo sus requisitos típicos, era sine qua non anticompetitiva, y lo que hizo la reforma fue simplemente eliminar uno de dichos requisitos: la

\footnotetext{
${ }^{42}$ Corte Suprema, Rol № 2578-2012, de 07 de septiembre de 2012.

43 BASCUÑÁN (2016), pp. 50-51: (...) Las hipótesis de las letras a), b) y c) del inciso segundo tienen la misma estructura (...) Así concebida su estructura formal, se puede afirmar que las tres infracciones descritas en el inciso segundo son casos sistemáticamente vinculados a la segunda hipótesis del inciso primero, esto es, a la infracción genérica de mera actividad y resultado cortado, y constituyen un atentado de peligro contra la libre competencia".

${ }^{44}$ BASCUÑÁN (2016), p. 175.

${ }^{45}$ De acuerdo a TAPIA (2010), p. 38, la exigencia de poder de mercado sería "meramente ratificador de que no todo acuerdo entre competidores es contrario a la libre competencia, sino sólo aquellos que confieren, actual o potencialmente, poder de mercado a las firmas coludidas. Ello no debe convertirse en un obstáculo para una interpretación que facilite la persecución de carteles y, sobre todo, para la aplicación de una regla per se". Asimismo, GRUNBERG y MONTT (2017), p. 326: "La frase "confieren poder de mercado" de la letra a) da cuenta de una definición de objeto y no de efecto, o si se quiere, de una presunción de efectos anticompetitivos que deriva de su propia naturaleza. Por el contrario, sería absurdo interpretar que dicha frase restringe la formulación amplia "tienda/tienden a producir dichos efectos" del inciso 1 o y del encabezado del propio inciso $2^{\circ}$, del cual la letra a) es un mero ejemplo".

46 Tribunal de Defensa de la Libre Competencia, sentencia 113-2011, de 19 de octubre 2010. La Corte Suprema revocó dicho fallo, aseverando que por “...el solo hecho de existir la concertación y que ésta busque modificar la conducta de un agente del mercado con el fin de obtener por parte de quienes deciden coludirse un beneficio de índole patrimonial, no puede ser sino tomado como un atentado contra los principios básicos que sustentan las normas que por medio del Decreto Ley № 211 se buscan salvaguardar...", Corte Suprema, Rol № 10.954-2011, de 27 de septiembre de 2012. Para un análisis de dichas sentencias, véase ARAYA (2012), pp. 238-244.

${ }^{47}$ Así, por ejemplo, AREEDA (1981), p. 21, proporciona una buena justificación para no exigir poder de mercado para condenar conductas como las de la letra a) del artículo 3o: "Una investigación sobre el poder de mercado no es socialmente gratuita, sino que requiere del gasto de recursos sociales de cortes y abogados, para probar o desacreditar el poder de las partes. No hay una buena razón para realizar dicho gasto si la conducta en cuestión carece totalmente de virtud redentora, tanto que la única cosa que se puede decir en favor de los acusados es que trataron de dañar al público pero que posiblemente no tenían el poder para hacerlo".
} 
necesidad de probar poder de mercado. En otras palabras, dado que la letra a) describe conductas que la ley ordena que se considerarán (siempre) anticompetitivas, resulta razonable entenderlas como aquellas que, concurriendo los requisitos del literal, son consideradas inequívocamente perniciosas o ineficientes.

A dicho respecto, el único fallo del TDLC que a la fecha se ha pronunciado sobre la materia, confirmado por la Corte Suprema, reconoce la aplicación de la regla per se en nuestra legislación post Ley № 20.945, adoptando una interpretación concordante con la que hemos venido sosteniendo. Ello en la ya citada Resolución 54-2018, al resolver sobre la consulta que formulara la Asociación Chilena de Empresas de Turismo A.G. en relación a acuerdos de joint venture que LATAM se proponía celebrar con líneas áreas competidoras de la misma (denominados Joint Business Agreements o JBA). En efecto, en la referida resolución la mayoría del TDLC indicó:

13. Lo anterior implica que aun cuando en términos generales los acuerdos entre competidores son mirados con sospecha por el derecho de la competencia, siendo fuerte la presunción en su contra, ellos no siempre son dañinos. En efecto, tales acuerdos bien pueden permitir a un grupo de firmas llevar a cabo actividades de forma más eficiente, sea por la escala alcanzada; por la reducción en costos informacionales, (...). Por ello, su propósito puede ser legítimo y socialmente deseable.

14. La cuestión radica en establecer de manera clara si un acuerdo produce o facilita comportamientos colusivos, de modo de poder establecer la eventual aplicación de la regla per se establecida en la letra a) del inciso 2o del artículo 3o del D.L. 211.

En ese caso particular, el TDLC estimó ${ }^{48}$ que los JBA no serían un tipo de acuerdo entre competidores presente en la "...experiencia habitual de las autoridades de competencia...", lo que volvería "...imposible derivar conclusiones claras a su respecto ...", por lo que no podrían ser calificados como acuerdos per se anticompetitivos y debía hacerse un análisis de sus riesgos y eficiencias, pese a que dichos acuerdos contemplaban, como parte de los mismos, la fijación de precios de común acuerdo.

Por su parte, al resolver sobre los recursos de reclamación interpuestos en contra de la referida sentencia, la Corte Suprema también fue explícita en indicar por qué no se aplicaba la regla per se en la especie, pese a que en el marco de los JBA se coordinaban variables competitivas de aquellas de la letra a) del artículo 30 :

Pues bien, en el caso concreto, para comprender la razón por la que no se aplica ipso facto la regla per se del artículo $3^{\circ}$ antes mencionado, resulta trascendente atender a la naturaleza de la ind ustria del transporte aéreo que, como se dijo, es una industria de redes, pues aquello determina que este tipo de acuerdos pueden ser necesarios no sólo para las empresas, sino que puedan además generar eficiencias (...) el quid del asunto radica en determinar si (...), efectivamente, la operación coordinada entre los competidores acarrea eficiencias tan significativas que neutralizan cualquier tipo de riesgo, pues sólo de esta forma se establecerá que el acuerdo es, como lo señalaron las partes, pro competitivo, pues esta situación es la que permite soslayar la regla prevista en el artículo $3^{\circ}$, inciso segundo, letra a) del Decreto Ley $N^{\circ} 211$.

Por último, en este punto, cabe indicar que, siendo el derecho de la competencia un derecho cuya regulación sustantiva es breve y está contenida en un solo artículo, el 3 o del DL 211, está esencialmente sujeto a la interpretación judicial, la que, por la naturaleza de la materia específica, debe informarse en buena medida por los principios económicos de la teoría de la competencia ${ }^{49}$. Ello obliga a considerar que existen ciertos tipos de acuerdos manifiestamente

\footnotetext{
48 Tribunal de Defensa de la Libre Competencia, resolución 54-2018, de 31 de octubre de 2018, punto 15.

${ }^{49}$ Véase MONTT (2009), p.1: "En materia de competencia, tenemos una verdadera rareza en términos de diseño institucional. El encargado de resolver los conflictos relativos a la protección de la competencia es un tribunal integrado por economistas y a bogados, que aplica básicamente una sola disposición legal -el artículo 3 del DL 211-, la que no dice nada o muy poco, y que, además, no se interpreta conforme a los artículos 19 y siguientes del código civil y la RAE, sino que de acuerdo a los dictados de la economía en general y de la organización industrial en particular".
} 
anticompetitivos que, en sí mismos, no admiten justificación alguna de eficiencia y que el sistema quiere evitar, cuestión sobretodo relevante en esta área del derecho, normativa esencialmente regulatoria y cuyo objetivo principal, como ya se indicó, es prevenir que ciertos riesgos anticompetitivos se materialicen en los mercados.

En suma y de forma muy relevante para una política de competencia efectiva, la lectura general del artículo 3 ㅇ y de su letra a) propuesta permite cumplir con los objetivos públicos de libre competencia, al concordar la existencia de reglas per se con la posibilidad de admitir defensas de eficiencia, para aquellos casos específicos que así lo ameriten.

De acuerdo a lo expuesto, los acuerdos entre competidores pueden analizarse bajo tres categorías distintas en nuestra legislación

Estimamos que una consecuencia lógica de lo que hemos venido sosteniendo en este trabajo es que nuestra legislación de libre competencia admite hoy tres categorías normativas de acuerdos entre competidores.

La primera se refiere a aquellos respecto de los cuáles la experiencia dicta que no son inequívocamente ineficientes y a los que es posible asignar ex ante justificaciones plausibles de eficiencia. Dichos acuerdos se analizan bajo el tipo genérico de infracción anticompetitiva del inciso primero del artículo 3 y su licitud depende de que las eficiencias inherentes a los mismos sobrepasen sus riesgos u efectos anticompetitivos, siendo ilícitos en caso contrario. Respecto de ellos, corresponde realizar un análisis amplio del mercado relevante y poder de mercado, así como de sus riesgos o efectos anticompetitivos y eficiencias.

La segunda y tercera categoría son aquellos de la letra a) del artículo 3o, que, en nuestra opinión, sanciona hoy dos categorías distintas de acuerdos:

(i) Aquellos referidos a precios, limitación de producción, cuotas o zonas de mercado y afectación de licitaciones: que "se considerarán" como hechos, actos o convenciones que impiden, restringen o entorpecen la libre competencia o que tienden a producir dichos efectos $y$;

(ii) Aquellos referidos a otras condiciones de comercialización o exclusión de competidores: que "se considerarán" como hechos, actos o convenciones que impiden, restringen o entorpecen la libre competencia o que tienden a producir dichos efectos, siempre que confieran poder de mercado a sus integrantes.

Así, estimamos que los acuerdos comprendidos en la letra a) son aquellos respecto de los que debe considerarse que siempre impiden, entorpecen o restringen la libre competencia o tienden a producir dichos efectos. En un caso (precios, cantidades, zonas o cuotas y licitaciones), con la mera concurrencia de ese tipo de acuerdo, y en el otro (otras condiciones de comercialización y exclusión de competidores), si es que además confieren poder de mercado.

De acuerdo a ello, la primera parte de la letra a) contiene una regla per se propiamente tal y la segunda parte una especie de regla per se menguada o sopesada, al exigirse la demostración de poder de mercado, equiparable esta última al análisis que realizaba la jurisprudencia respecto de la letra a) con anterioridad a la reforma legal.

En otras palabras, la letra a) en su primera parte castiga propiamente a los acuerdos duros o restricciones desnudas y en su segunda, a cierto tipo de acuerdos que, confiriendo poder de mercado, son equiparables en su análisis y consecuencias a los carteles duros ${ }^{50}$. En el primer caso, acreditado el acuerdo, se considera, por expresa disposición legal, que el mismo es anticompetitivo (afecta o tiende a afectar la libre competencia). En el segundo, probado el acuerdo y el poder de mercado, la consideración debe ser la misma. En ambas situaciones

\footnotetext{
50 Por ejemplo, es posible imaginar la existencia de acuerdo entre los incumbentes de una industria para evitar que una nueva tecnología disruptiva, más barata o de mejor calidad, ingrese a la misma, lo que podría materializarse por ejemplo a través de imposición de estándares no razonables en el marco de una Asociación Gremial. Como puede entenderse, dicha conducta es claramente ineficiente y efectuada por incumbentes con poder de mercado resulta claro su potencial anticompetitivo.
} 
tampoco procede un análisis de eficiencias, al establecer la ley que son acuerdos respecto de los que "se considera" que afectan la libre competencia o tienden a ello.

\section{Conclusiones}

En el presente trabajo se planteó el problema de si era posible concordar la regla per se introducida por la Ley №20.945 respecto de los acuerdos de precios, cantidad, zonas o cuotas de mercado y afectación de licitaciones, con la posibilidad de alegar que, en ciertas circunstancias, los acuerdos sobre dichas variables pueden ser socialmente eficientes o beneficiosos.

Como se expuso, resulta jurídicamente errado e inconveniente como política de competencia interpretar que sería posible alegar eficiencias respecto de dichas variables por las siguientes vías: i) considerar que, por lo dispuesto en el inciso 1ㅇd del artículo 30 siempre debe probarse una afectación de la competencia respecto de los literales del inciso segundo o; ii) estimar que dichos literales contienen presunciones legales.

En nuestra opinión, la forma correcta de analizar conceptualmente el problema planteado dice relación con que lo per se corresponde a una categoría de análisis y no a una tipología de conductas específicas delimitadas por la variable competitiva afectada. De dicha forma, los acuerdos entre competidores que pueden ser analizados bajo la letra a) son siempre aquellos que se refieren a las variables ahí indicadas y que plausiblemente no admiten justificaciones de eficiencia. Ello se condice con la estructura típica del artículo 3으, norma que establece que la letra a) y los demás literales del inciso segundo son casos en que, cumplidos los requisitos típicos, el legislador considera o da por hecho que la libre competencia se ve afectada o que se tiende a dicha afectación.

De acuerdo a ello, nuestra legislación concibe actualmente tres tipos de acuerdos entre competidores: i) aquellos propiamente per se, de la primera parte de la letra a); ii) aquellos per se calificados por la posición de dominio, de la segunda parte de la letra a) y; iii) aquellos analizables en sus riesgos y eficiencias bajo el inciso primero del artículo 3o y que también pueden decir relación con las variables competitivas propias de los tipos anteriores.

Estimamos que la clasificación por parte del TDLC de los casos concretos que se le presenten en alguna de las tres categorías resulta una tarea casuística no sencilla de realizar y no exenta de problemas prácticos y procesales, como por ejemplo, si el carácter de acuerdo sujeto a la letra a) se va a determinar en una etapa temprana del juicio (como podría ser la interlocutoria de prueba) o solo en la sentencia final, admitiéndose por tanto prueba de eficiencias durante todo el juicio, cuestión que, por un lado, otorgaría mayores garantías procesales, pero por otro, atentaría contra los ahorros de costos que la regla per se intenta generar.

Pero no obstante ello, nos parece que las soluciones a dichos problemas son justamente, adjetivas o procesales y no deberían afectar la consideración sustantiva de la norma que hemos esbozado en el presente trabajo, la que, en nuestra opinión, es la que mejor se aviene con el texto legal, la historia fidedigna del establecimiento del precepto, la jurisprudencia y los fines de política pública que motivan la introducción de reglas per se en materia de libre competencia.

\section{BIBLIOGRAFÍA CITADA}

ARAYA, FERNANDO (2012): “Una lectura deontológica del requisito de aptitud objetiva del acuerdo entre competidores para afectar la libre competencia. Corte Suprema, 27 de septiembre de 2012, rol 10.954-2011", en: Revista Chilena de Derecho Privado (№ 19), pp. 238-244

AREedA, PhILLIP (1981): "The Rule of Reason in Antitrust Analysis: General Issues", en: Washington D.C., The Federal Judicial Center. Disponible en: https://bit.ly/2PTdMsm [visitado el 19 de marzo de 2020]. 
BARROS, ENRIQUE (2011): Tratado de Responsabilidad Extracontractual (Santiago, Editorial Jurídica de Chile).

BASCUÑÁN, ANTONIO (2016): Estudios sobre la Colusión (Santiago, Thomson Reuters).

Biblioteca Del Congreso Nacional De Chile (2016): “Historia de la Ley № 20.945". Disponible en: https://bit.ly/3b3Wq3b [visitado el 16 de marzo de 2020].

BORK, ROBERT (1966): "The Rule of Reason and the Per Se Concept: Price Fixing and Market Division", en: Yale Law Journal (Vol. 75, № 3), pp. 373-476.

BRUZZONE, GINEVRA Y CAPOZZI, SARA (2015): "Restrictions by Object in the Case Law of the Court of Justice: In Search of a Systematic Approach", en: Benacchio, Gian Antonio y Carpagnano, Michele (Eds.), 'L'applicazione delle regole di concorrenza in Italia e nell'Unione europea. Atti del V Convegno biennale Antitrust di Trento' (Trento, Editoriale scientifica). Disponible en: SSRN: https://bit.ly/3b2Aqpg [visitado el 16 de marzo de 2020].

COMISIÓN EUROPEA (2011): “Comunicación de la comisión: Directrices sobre la aplicabilidad del artículo 101 del Tratado de Funcionamiento de la Unión Europea a los acuerdos de cooperación horizontal (2011/C 11/01)". Disponible en: https://bit.ly/3h1CNgb [visitado el 19 de marzo de 2020].

De La Mano, Miguel; NazzinI, Renato y Zenger, Hans (2014): “Article 102": en Faull, Jonathan y Nikpay, Ali (Eds.), The EU Law of Competition, 3a edición (Oxford, Oxford University Press), pp. 329-538.

Faull, Jonathan; KJolbye, LaRS; LeUpold, Henning y NiKPay, Ali (2014): “Article 101", en: Faull, Jonathan y Nikpay, Ali (Eds.), The EU Law of Competition, 3a edición (Oxford, Oxford University Press), pp. 183-328.

Federal Trade Commission y U.S. Department Of Justice (2000): “Antitrust Guidelines for Collaborations Among Competitors". Disponible en: https://bit.ly/3hOrAMC [visitado el 15 de marzo de 2020].

Fiscalía NACIONAL ECONÓMICA (2012): "Guía para el Análisis de Operaciones de Concentración". Disponible en: https://bit.ly/3vHJ8Br [visitado el 15 de marzo de 2020].

(2013): "Participaciones minoritarias y directores comunes entre empresas competidoras". Disponible en: https://bit.ly/3b2jIXi [visitado el 16 de marzo de 2020].

GRUNBERG, JORGE (2020): "Regla per se para carteles duros y acuerdos de colaboración entre competidores: un problema regulatorio aparente", en: Investigaciones Centro Competencia Universidad Adolfo Ibáñez. Disponible en https://bit.ly/3tdJQEU [visitado el 15 de marzo de 2020].

Grunberg, JoRge y MontT, SANTiAgo (2017): “La Prueba de la Colusión”, en: Fiscalía Nacional Económica, Reflexiones sobre el Derecho de la Competencia: Informes en Derecho solicitados por la Fiscalía Nacional Económica (2010-2017) (Santiago, Ediciones de la Fiscalía Nacional Económica), pp. 305-383.

HenRY, RoXANNe (2016): Primer on per se treatment under U.S. antitrust law (Washington D.C., American Bar Association Section of Antitrust Law, 64th Annual Antitrust Spring Meeting).

HOVENKAMP, HeRBert (2008): "The Antitrust Standard for Unlawful Exclusionary Conduct", en: Faculty Scholarship at Penn Law, 1777. Disponible en: https://bit.ly/3uokVzY [visitado el 19 de marzo de 2020].

(2018): "The Rule of Reason", en: Faculty Scholarship at Penn Law, 1778. Disponible en https://bit.ly/3xPL6kX [visitado el 19 de marzo de 2020]. 
(2019): “Is Antitrust's Consumer Welfare Principle Imperiled?", en: Faculty

Scholarship at Penn Law. $1985 . \quad$ Disponible en: https://bit.ly/2QMAldm [visitado el 15 de marzo de 2020].

MontT, SANTIAgo (2009): El Tribunal de Defensa de la Libre Competencia Como Ente Regulador del Comercio: Una Mirada Desde las Políticas Públicas, Documento de Trabajo № 1 (Santiago, Centro de Regulación y Competencia - Universidad de Chile).

(2017): “Condiciones Impuestas por el Tribunal de Defensa de la Libre Competencia en el Marco de un Operación de Concentración en el Derecho Chileno", en: Fiscalía Nacional Económica, Reflexiones sobre el Derecho de la Competencia: Informes en Derecho solicitados por la Fiscalía Nacional Económica (2010-2017) (Santiago, Ediciones de la Fiscalía Nacional Económica), pp. 81-114.

MoRAIS, LUís (2013): "Horizontal cooperation agreements", en: Geradin, Damien y Lianos, loannis (Eds.), Handbook on European Competition Law (Cheltenham, Edward Elgar Publishing Limited), pp. 85-129.

SAloP, SteVen (2010): "Question: What Is the Real and Proper Antitrust Welfare Standard? Answer: The True Consumer Welfare Standard", en: Loyola Consumer Law Review (Vol. 22, № 3), pp. 336-353.

(2016): "Evaluating Joint Ventures: Economic Analysis Checklist", en: Georgetown Law Faculty Publications and Other Works. Disponible en https://bit.ly/3aZKbF2 [visitado el 15 de marzo de 2020].

TAPIA, JAVIER (2010): “Informe en Derecho: La Prohibición de Colusión en el Derecho Chileno y Comparado. Santiago, Chile, Tribunal de Defensa de la Libre Competencia, autos C-177-08, caratulados "Requerimiento de la FNE contra ACHAP A.G y Otros"”. Disponible en: https://bit.ly/3nM6z9U [visitado el 19 de marzo de 2020].

Tribunal De Defensa De La libre Competencia (2016): "Cuenta Pública del Presidente del Tribunal de Defensa de la Libre Competencia, don Tomás Menchaca Olivares". Disponible en: https://bit.ly/3xP43UO [visitado el 15 de marzo de 2020].

VALDÉs, DomIngo (2006): Libre Competencia y Monopolio (Santiago, Editorial Jurídica de Chile).

WHISH, RICHARD (2015): "Observations on the proposed amendments to the chilean competition law". Disponible en: https://bit.ly/3h1tdtz [visitado el 15 de marzo de 2020].

WHISH, RICHARD Y BAILEY, DAVID (2012): Competition Law, 7a Edición (Oxford, Oxford University Press).

JURISPRUDENCIA CITADA

BROAdCASt MUSIC, INC. v. ColUMBia BROAdCASTING SYSTEM, Inc. 441 U.S. 1, 9 (1979).

NoRthwest Wholesale Stationers V. Pacific Stationary \& Printing Co., 472 U.S. 284, 289 (1985).

SOlICITUD DE MODIFICACIÓN DEL DiCTAMEN № 992, de 25 de noviembre de 1996, de la H. Comisión Preventiva Central (2006): Tribunal de Defensa de la Libre Competencia 16 de noviembre de 2006 (procedimiento no contencioso 18 № 2 DL 211), en: https://bit.ly/33fS98C

Demanda de Voissnet S.A. contra Compañía de Telecomunicaciones de Chile S.A. (2010): Tribunal de Defensa de la Libre Competencia 4 de marzo de 2010 (procedimiento contencioso 18 № 1 DL 211), en: https://bit.ly/3eVrm6S

Requerimiento DE LA F.N.E. CONTRA FARMACIAS AhUmAdA y OtRos (2012): Corte Suprema 07 de septiembre de 2012 (recurso de reclamación art. 27 DL 211), en: https://bit.ly/3vHJDvj 
REQUERIMIENTO DE LA FNE CONTRA ABERCROMBIE \& KENT S.A. Y OtROS (2012): Tribunal de Defensa de la Libre Competencia 20 de septiembre de 2012 (procedimiento Contencioso 18 №1 DL 211), en: https://bit.ly/3tot59T

CONSULTA DE SMU S.A. SOBRE LOS EFECTOS EN LA LIBRE COMPETENCIA DE LA FUSIÓN DE LAS SOCIEDADES SMU S.A. Y SUPERMERCADOS DEL SUR S.A. (2012): Tribunal de Defensa de la Libre Competencia 12 de diciembre de 2012 (procedimiento no contencioso 18 № 2 DL 211), en: https://bit.ly/3tiBxrr

Requerimiento de la FNE contra CASTHer y OtRos (2014): Tribunal de Defensa de la Libre Competencia 19 de junio de 2014 (procedimiento contencioso 18 № 1 DL 211), en: https://bit.ly/3nPotbG

DeMANDA DE CONDOMINIO CAMPOMAR CONTRA INMOBILIARIA SANTA ROSA DE TUNQUÉN (2014): Tribunal de Defensa de la Libre Competencia 4 de noviembre de 2014 (procedimiento contencioso 18 № 1 DL 211), en: https://bit.ly/2RnKQZY

Requerimiento de LA FNE CONTRA LA Asociación GRemial de Ginecólogos ObSTETRAS de LA PRovinCIA de ÑUble Y Otros (2015): Tribunal de Defensa de la Libre Competencia 1 de abril de 2015 (procedimiento contencioso 18 № 1 DL 211), en: https://bit.ly/3nOswoN

Requerimiento de la FNE contra Agrícola Agrosuper S.A. y otros (2015): Corte Suprema 29 de octubre de 2015 (recurso de reclamación art. 27 DL 211), en: https://bit.ly/3h1ywsR

Requerimiento de LA FNE CONTRA Asfaltos Chilenos S.A. y otros (2015): Tribunal de Defensa de la Libre Competencia 23 de diciembre de 2015 (procedimiento contencioso 18 № 1 DL 211), en: https://bit.ly/2Roa3DB

Requerimiento de la fNe contra Asfaltos Chilenos S.A. Y otros (2016): Corte Suprema 12 de octubre de 2016 (recurso de reclamación art. 27 DL 211), en: https://bit.ly/3eOVLUq 5128-2016.

CONSULTA DE LA ASOCIACIÓN CHILENA DE EMPRESAS DE TURISMO A.G. SOBRE OPERACIÓN DE CONCENTRACIÓN LATAM AIRLINES GROUP, AMERICAN AIRLINES INC. Y OtRAS (2018): Tribunal de Defensa de la Libre Competencia 31 de octubre de 2018 (procedimiento no contencioso 18 № 2 DL 211), en: https://bit.ly/2RsLTHL

Requerimiento de la fiscalía nacional EConómica en contra de Cencosud S.A. y otras (2019): Tribunal de Defensa de la Libre Competencia 28 de febrero de 2019 (procedimiento contencioso 18 № 1 DL 211), en: https://bit.ly/3xKmwlv

Consulta de la Asociacion ChILENA de EMPRESAS de TURISMO AG. SOBRE OPERACION DE CONCENTRACION LATAM GROUP AMERICAN AIRLINES INC. Y OTRAS (2019): Corte Suprema 23 de mayo de 2019 (recurso de reclamación art. 27 DL 211), en: https://bit.ly/3h1yBg9

Asunto C-307/18 Generics (UK) v Competition and Markets Authority (2020): Tribunal Europeo de Justicia, en: https://bit.ly/3umrh2u

\section{NORMAS JURÍDICAS CITADAS}

DeCRETO CON FUeRZA de Ley № 1 del Ministerio de ECONOMía, Fomento y Turismo de 2015, que fija el texto refundido, coordinado y sistematizado del Decreto Ley $N^{\circ} 211$ de 1973. Diario Oficial, 7 de marzo de 2005.

LEY № 20.945, perfecciona el sistema de defensa de la libre competencia. Diario Oficial, 30 de agosto de 2016.

TRATADO DE FUNCIONAMIENTO DE LA UNIÓN EUROPEA. 